\title{
KNOWLEDGE, ATTITUDE AND EXPERIENCE OF MENOPAUSE - AN URBAN BASED STUDY IN BANGLADESH
}

\author{
TANIRA $\mathrm{S}^{1}$, WAZED $\mathrm{F}^{2}$, SULTANA $\mathrm{A}^{3}$, AMIN $\mathrm{R}^{4}$, SULTANA $\mathrm{K}^{5}$, AHMAD $\mathrm{S}^{6}$
}

\begin{abstract}
:
A cross-sectional descriptive study was designed to determine the knowledge and attitude of postmenopausal women towards menopause and symptoms experienced by them. A total of 1056 women of 40-87 years of age were interviewed on the basis of a semi-structured questionnaire. The study was conducted in different non-government primary health care service centres as well as out patient department of tertiary government hospitals and private hospitals in Dhaka city from February to August 2008. The collected data were analyzed by using the SPSS 11.0 version. 994 (94.13\%) had natural menopause and surgical menopause was evident only in $62(5.87 \%)$ cases. $33.52 \%$ women were quite illiterate and $44.70 \%$ were of poor socioeconomic condition. $45.27 \%$ knew about the age of menopause and $34.75 \% \mathrm{knew}$ the possible health effects of menopause. $82.58 \%$ of women considered it as a natural process and $17.42 \%$ perceived it as a disease. $26.14 \%$ were happy having no menstruation but $54.92 \%$, being unhappy, wanted to have menses again and $18.94 \%$ had no opinion. Most common physical symptoms reported were backache (82.77\%), bodyache (65.25\%), insomnia (45.27\%), vasomotor symptoms like hot flushes (36.84\%) and night sweats (32.39\%) and frequent mental symptoms were mood changes (34.85\%), loss of memory (19.70\%) and depression (19.51\%). $32.47 \%$ were bothered by those symptoms but only 18.23\% consult the physician. Only $3.67 \%$ were taking HRT. The overall scenario is frustrating, though the people were from a more facilitated environment of a mega city like Dhaka, and that may be due to low literacy rate and poverty.
\end{abstract}

Key words: menopause, awareness, menopausal symptoms, reproductive health.

J Dhaka Med Coll. 2009; 18(1) : 33- 36

\section{Introduction:}

Reproductive health has become an important norm in today's health system. The menopause is a transitional developmental period in women's life and an essential part of reproductive health care ${ }^{1}$. It occurs usually between the ages of 45 and 52 years but may vary. The average age of menopause in western countries has risen by 5 years in the last century, a change which probably reflects a general improvement in health and vigour of the community and a determination of women to stay young ${ }^{2}$. The menopause is a period of decreasing ovarian function and diminished oestrogen level, followed by cessation of menstruation. However, for the middle-aged women, this loss is a critical issue as it represents the end of fertility and onset of aging process. Due to diminished oestrogen level, a variety of symptoms such as hot flushes, mucosal dryness, excessive sweating, emotional fluctuations, psychoses, decreased strength and calcification of bones throughout the body, are experienced by

1. Coordinator (Health), MCH-FP Clinic, Manabik Shahajya Sangstha (MSS), Dhaka.

2. Medical Officer, OPD, Department of Obstetrics \& Gynaecology, Dhaka Medical College Hospital, Dhaka.

3. Registrar, Department of Obstetrics \& Gynaecology, Apollo Hospitals, Dhaka.

4. Medical Officer, Department of Obstetrics \& Gynaecology, BIRDEM Hospital, Dhaka.

5. Medical Officer, Smiling Sun Clinic, Lalbagh, Dhaka.

6. OSD, Directorate General of Health Services (DGHS), Dhaka.

Correspondence: Dr. Shaorin Tanira 
women in menopause ${ }^{3}$. It is important to understand the changes, take medical help, whenever necessary, and adopt a healthy life style, proper nutrition and positive attitude. In fact, this is a period when women can contribute to the happiness of the family, friends and society in many ways ${ }^{4}$. Multiple factors including socioeconomic background, education, job and family environment, physical and mental health influence women's beliefs and knowledge about menopause and attitude towards it. Moreover, these factors may alter the experience of menopausal symptoms as well as health seeking behaviour ${ }^{5}$. Especially in societies where it is not viewed as negative rather a positive event, the symptoms are found less common ${ }^{6}$. Urban population has got various ways to be facilitated with employment, education, health facilities and mass media communication. Therefore, public awareness and participation in health related activities is expected to be more in urban areas. The present study is an approach to evaluate women's knowledge, attitude and health problems related to menopause in an urban population.

\section{Methods:}

A cross-sectional descriptive study was done from February to August 2008 based on convenient sampling i.e. female patients having menopause and seeking treatment at different health service centres in Dhaka city including tertiary government hospitals like Dhaka Medical College Hospital, private institutes like BIRDEM Hospital, Apollo Hospitals, and NGOs like MCH-FP Clinic of MSS, 'Smiling Sun' Clinics, and few chambers of General Practitioners. A total of 1056 women were interviewed after a primary selection, age ranging from 40 to 87 years. The patient selection criteria were followed strictly based on the definition of menopause as per given by $\mathrm{WHO}^{7}$. Women who had experienced amenorrhoea for 12 or more consecutive months, were considered to be in natural menopause. Women with a history of surgical removal of both the ovaries (with or without hysterectomy), were considered to be in surgical menopause. Both natural and surgical menopausal women are included into this study. Informed consent was taken verbally. A predesigned questionnaire was used to collect the information from the patients regarding their sociodemographic status, knowledge and attitude towards menopause and experience of menopausal symptoms. The collected data were analyzed by using the SPSS 11.0 version.

\section{Results:}

Analyzing the results, it was found that the age of women ranged from 42 to 87 and the mean age was $53.24 \pm 4.17$ years. Most of the women $(94.3 \%)$ had natural menopause and surgical menopause was evident only in $5.6 \%$ cases. $33.52 \%$ women were quite illiterate and $44.70 \%$ were of poor socioeconomic condition. $45.27 \%$ knew about the age of menopause and $34.75 \%$ knew the possible health effects of menopause. $82.58 \%$ of women considered it as a natural process and $17.42 \%$ perceived it as a disease. $26.14 \%$ were happy having no menstruation but $54.92 \%$, being unhappy, wanted to have menses again and $18.94 \%$ had no opinion. Most common physical symptoms reported were backache $(82.77 \%)$, bodyache $(65.25 \%)$, insomnia (45.27\%), vasomotor symptoms like hot flushes (36.84\%) and night sweats (32.39\%) and frequent mental symptoms were mood changes (34.85\%), loss of memory (19.70\%) and depression (19.51\%). 32.47\% were bothered by those symptoms but only $18.23 \%$ consult the physician. Associated diseases were hypertension (65.80\%) and Diabetes mellitus (43.66\%) for which actually they used to consult the physician. Only $3.67 \%$ were taking HRT. Knowledge about menopause has been commonly learnt from the older family members (60.61\%) and friends $(37.12 \%)$, little from reading material or TV. The results of the study are presented in Table: I, II \& III. 
Table-I

Sociodemographic characteristics ( $n=1056)$

\begin{tabular}{lcc}
\hline Age of women (in years) & Number & $\%$ \\
\hline $40-49$ & 658 & 62.31 \\
$50-59$ & 185 & 17.52 \\
$60-69$ & 143 & 13.54 \\
$70-79$ & 48 & 4.55 \\
$80-89$ & 22 & 2.08 \\
Parity of women & & \\
Nulliparous & 17 & 1.61 \\
$1-2$ & 754 & 71.40 \\
3-4 & 231 & 21.88 \\
5-6 & 41 & 3.88 \\
$7-8$ & 7 & 0.66 \\
$>8$ & 6 & 0.57 \\
Marital status & & \\
Married & 797 & 75.47 \\
Widow & 219 & 20.74 \\
Divorcee & 40 & 3.79 \\
Education & & \\
Nil & 354 & 33.52 \\
Primary & 198 & 18.75 \\
High school & 241 & 22.83 \\
College & 105 & 9.94 \\
University & 158 & 14.96 \\
Socio-economic status & & \\
Poor & 472 & 44.70 \\
Low middle class & 213 & 20.17 \\
Upper middle class & 287 & 27.18 \\
Elite & 84 & 7.95 \\
\hline
\end{tabular}

Table-II

Knowledge and attitude towards menopause

\begin{tabular}{lcc}
\hline Level of knowledge & Number & $\%$ \\
\hline Knowledge about: & & \\
Age of menopause & 478 & 45.27 \\
$\begin{array}{l}\text { Menpausal symptoms } \\
\text { Perception of menopause: }\end{array}$ & 367 & 34.75 \\
No opinion & 200 & 18.94 \\
Normal aging process & 872 & 82.58 \\
$\begin{array}{l}\text { Disease } \\
\text { Happy about menstrual }\end{array}$ & 184 & 17.42 \\
cessation & 276 & 26.14 \\
Worried about menstrual & 580 & 54.92 \\
cessation & & \\
\hline
\end{tabular}

Table-III

Experience of menopausal symptoms

\begin{tabular}{lcc}
\hline Symptoms & Number & $\%$ \\
\hline Backache & 874 & 82.77 \\
Bodyache & 689 & 65.25 \\
Insomnia & 478 & 45.27 \\
Hot flushes & 389 & 36.84 \\
Mood Changes & 368 & 34.85 \\
Night sweats & 342 & 32.39 \\
Loss of memory & 208 & 19.70 \\
Depression & 206 & 19.51 \\
Loss of libido & 187 & 17.71 \\
Dyspareunia & 142 & 13.45 \\
Frequent micturition & 132 & 12.50 \\
Weight gain & 117 & 11.08 \\
Associated problems & & \\
Hypertension & 461 & 43.66 \\
Diabetes Mellitus & 378 & 35.80 \\
\hline
\end{tabular}

\section{Discussion:}

Earlier studies have shown that women of developing countries are still lagging behind in health matters like menopause $6,8,9,10$. Our study has also revealed the same, though urban women were selected for the study and expected to respond in a better way. Women learn to respond to the menopausal symptoms in an individual and culturally dependent way $6,8,11,12,13$. A low prevalence of menopausal symptoms and its medical attention has been reported by those studies of south and eastern Asian, African and Latin American countries $4,6,7,8,9,10,14$, while a high prevalence has been found in some of the developed middle eastern and western countries ${ }^{5,11.12,15}$. The lower prevalence is also evident in the present study, and may be due to lack of knowledge, awareness, less medical facilities and poverty. A perception of the menopause as a positive event also varies in different countries between $40-90 \% 5,8,10,11$. Ours low positive perception may be the result of thinking of the menopause as the end of fertility, feminity and sexuality. This parameter also has been influenced by the age, parity, education and socioeconomic status ${ }^{5,16}$. Several factors have been found in the present study influencing women's perception and attitude towards menopause e.g. age, parity, education, socioeconomic condition, employment etc. Positive attitude found in highly educated, upper 
middle class and elite women. Treatment seeking attitude found in only few highly educated and elite women who could manage the costs of hormone replacement therapy (HRT). Most of the participants actually came to the physician for associated diseases. Earlier studies have revealed the fact that even who have some ideas or knowledge about menopause, do not put into practice in their behaviour yet ${ }^{7,16,17}$. Similar views have been found in the present study. Knowledge about menopause has been commonly learnt from the older family members $(60.61 \%)$ and friends $(37.12 \%)$, little from reading material or TV. It signifies that health education and mass media communication are still inadequate.

\section{Conclusion:}

With increase in life expectancy throughout the world, most of the women will live through menopause and urbanization causes more stressful life as well as increased vulnerability to perimenopausal and postmenopausal health problems. Management of menopause with the hormone replacement therapy (HRT) is not always justifiable in a poor developing country like Bangladesh, as costs of pretherapeutic investigations and medications are very high. Moreover, management of menopause is not only the HRT but a holistic approach to health where medical treatment along with social and psychological support, physical exercise and appropriate life style are to be ensured. Medical service providers and health promotion and education department should take necessary measures to increase public awareness about psychosocial impact of menopause and improve the quality of life of women through behavioural change communication (BCC).

\section{Acknowledgement:}

We would like to express our gratitude to the participants of the study and special thanks to the authority of MCH-FP project of Manabik Shahajya Sangstha (MSS), Dhaka for the technical back up and Dr. Abu Sadat Mohammad Nurunnabi of Dhaka Medical College for his valuable suggestions, guidance and strong encouragement to complete this work.

\section{References:}

1. Pradhan A. Women, health policy and development. Kathmandu Univ Med J. 2003; 1(4): 294-6.
2. Kumar P, Malhotra N. eds. Jeffcoate's principles of gynaecology. $7^{\text {th }}$ ed. New Delhi: Jaypee; 2008. p.91-100.

3. Guyton AC, Hall JE. Female physiology before pregnancy and female hormones. In: Text book of medical physiology. $11^{\text {th }}$ ed. New Delhi: Elsevier; 2006. p.1011-25.

4. Sharma VK, Saxena MS. Climacteric symptoms: a study in the Indian context. Maturitus. 1981; 3(1): 11-20.

5. Avis NE, McKinlay SM. A longitudinal analysis of women's attitudes towards the menopause: results from the Massachusetts Women's Health Study. Maturitas. 1991; 13(1): 65-79.

6. Pan $\mathrm{Ha}$, Wu $\mathrm{MH}$, Hsu CC, Yao BL, Huang KE. The perception of menopause among women in Taiwan. Maturitas. 2002; 41(4): 269-74.

7. Nacar M, Baykan Z, Cetinkaya F. Perceptions and attitudes towards the menopause: a study from Kayseri. Turkish J Pub Health. 2008; 6(2): 3645.

8. Adekunle AO, Fawole AO, Okunlola MA. Perceptions and attitudes of Nigerian women about the menopause. J Obstet Gynaecol. 2000; 20(5): 525-9.

9. Velasco MV, Navarrete HE, Ojede MRI. Experience and knowledge about climacteric \& menopause in women in Mexico city. Ged Med Mex. 2000; 136(6): 555-64.

10. Baig LA, Karim SA. Age at menopause, and knowledge of and attitudes to menopause, of women in Karachi, Pakistan. J Br Menopause Soc. 2006 ; 12(2): 71-4.

11. David M, Borde T, Kentenich H. Female menopause - comparison of knowledge and opinion in German and Turkish-born women. [Abstract]. Zentralbl Gynakol. 2001; 123(1): 3-9.

12. Rizk DE, Bener A, Ezimokhai M, Hassan MY, Micallef R. The age and symptomatology of natural menopause among United Arab Emirates' women. Maturitas. 1998; 29(3): 197-202.

13. Lock M. Ambiguities of aging: Japanese experience and perceptions of menopause. Cult Med Psychiatry. 1986; 10(1): 23-46.

14. Chen YL, Voda AM, Mansfield PK. Chinese midlife women's perceptions and attitudes about menopause. Menopause. 1998; 5(1): 28-34.

15. Chim H, Tan BH, Ang CC, Chew EM, Chong YS, Saw SM. The prevalence of menopausal symptoms in a community in Singapore. Maturitus. 2002; 41(4): $\quad 275-82$.

16. Nusrat $N$, Nishat $Z$, Gulfareen $H$, Aftab M, Asia $\mathrm{N}$. Knowledge, attitude and experience of menopause. J Ayub Med Coll. 2008; 20(1): 56-9.

17. Sallam H, Galal AF, Rashed A. Menopause in Egypt: past and present perspectives. Climacteric. 2006; 9(6): 421-9. 